\title{
Terminal porosity and the geochemical detectability of plutonic residues of melt extraction
}

\author{
$\mathrm{Ke} \mathrm{GAO}^{1}$, C. Brenhin Keller ${ }^{2 *}$, ChangQian MA ${ }^{1}$ \\ ${ }^{1}$ State Key Laboratory of Geological Process and Mineral \\ Resources, School of Earth Sciences, China University of \\ Geosciences, Wuhan, Hubei, 430074, P.R. China \\ (gaoke@cug.edu.cn, cqma@cug.edu.cn) \\ 2 Department of Earth Sciences, Dartmouth College, Hanover, NH \\ 03755, USA (*correspondence: cbkeller@dartmouth.edu)
}

The geological and geochemical relationship between volcanic and plutonic rocks has long been a subject of debate. High-silica volcanic rocks, especially rhyolites, are often interpreted as the product of interstitial melt extraction from a crystal-rich magma reservoir, leaving behind a plutonic cumulate residue. However, analysis of volcanic and plutonic whole-rock geochemical datasets at global scale suggests that, on average, high-silica plutonic rocks are no more cumulate in nature than their volcanic equivalents $[1$, 2].

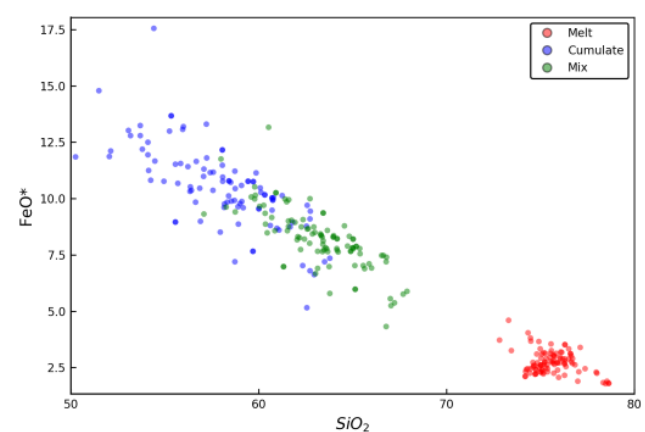

Figure 1. Comparison of melt, cumulate, and (to simulate the effects of terminal porosity) a melt-cumulate mix, where cumulate is combined with $30 \%$ residual melt (wt $\%)$.

Here we use trace- and major-element alphaMELTS [3] geochemical modelling to test the hypothesis $[4,5]$ that $\sim 30 \%$ residual melt trapped by the terminal porosity of the plutonic residue of rhyolitic melt extraction masks the cumulate signature thereof. Our analysis indicates that the geochemical differences between extracted melts and cumulate residues remain readily resolvable even when accounting for the effects of interstitial melt trapped by to the terminal porosity of a compacting crystal mush.

[1] Keller et al. (2015) Nature 523, 301-307.[2] Glazner et al. (2015) Physical geology of shallow magmatic systems, 61-82. [3] Ghiorso et al. (2002) Geochem. Geophys. Geosyst. 3, 1-36. [4] Schaen et al. (2017) Geology 45, 835-838.[5] Lee \& Douglas, (2015) EPSL 409, 23-31. 